\title{
Titel/Title: Two Worlds of Academic Publishing: Chemistry and German Sociology in Comparison
}

Autor*innen/Author(s): Markus Rost

Uwe Schimank

Ute Volkmann

Veröffentlichungsversion/Published version: Postprint

Zeitschriftenartikel/Journal article

\section{Empfohlene Zitierung/Recommended citation:}

Rost, Markus/ Schimank, Uwe/ Volkmann, Ute (2014): Two Worlds of Academic Publishing: Chemistry and German Sociology in Comparison. In: Minerva, 52, 187-212.

Verfügbar unter/Available at:

(wenn vorhanden, bitte den DOI angeben/please provide the DOI if available)

This is a post-peer-review, pre-copyedit version of an article published in Minerva. The final authenticated version is available online at: https://doi.org/10.1007/s11024-014-9251-4

Zusätzliche Informationen/Additional information:

The author can be contacted at: uwe.schimank@uni-bremen.de 


\title{
Two Worlds of Academic Publishing: Chemistry and German Sociology in Comparison
}

Ute Volkmann $\cdot$ Uwe Schimank $\cdot$ Markus Rost

\begin{abstract}
The communication infrastructure of modern science is provided by profit-oriented business firms: the publishing houses which print and distribute academic books and journals. Surprisingly, beyond some rather superficial impressions, in science studies little is known about how academic publishers work - in particular, how markets for books and journals look like, how publication decisions are taken, and how the interplay with the scientific community is arranged. We address these questions with a focus on the relation between economic considerations of publishers, on the one hand, and the requirements of scientific communication, on the other. Our contrasting case studies are a very large world- wide operating publisher with regard to chemistry publications and a national publishing house of German sociology. At first, we show how the rather different business approaches of the two types of academic publishing houses look like. Both approaches could reach stability for some time which means not only that publishers earned money according to their profit aspirations but also that the communication requirements of science were sufficiently met. Afterwards, we point out the instabilities that have begun to arise in both fields and may sooner or later erode the former fit of profit-making and scientific communication.
\end{abstract}

Keywords Academic publishing • Publishing business • Scientific communication $\cdot$ Open access $(\leftarrow$ p. 187)

This article is based on our presentation at the sub-theme "Organizing Science: The Increasingly Formal Structuring of Academic Research", at the EGOS Colloquium 2012 in Helsinki, July 5-7.

U. Volkmann (\&) U: Schimank M. Rost

Universität Bremen, Fachbereich 08/Sozialwissenschaften, Institut für Soziologie,

Mary-Somerville-Straße 9, 28359 Bremen, Germany

e-mail: ute.volkmann@uni-bremen.de 


\section{Introduction}

For a long time modern science has lived quite well with the arrangement that its communication infrastructure is provided by profit-oriented business firms: the publishing houses which print and distribute academic books and journals. ${ }^{1}$ The growth of modern science has been accompanied by a corresponding growth of academic publishing as a sub-sector of the publishing industry. We have become accustomed to that arrangement. But its fragility has become apparent as a result of developments that have been going on for more than twenty years now.

Looking first at STM (science, technology, and medicine) disciplines, scientists' and librarians' complaints about excessively growing journal prices have become louder. A recent incident was an online-declaration issued in January 2012 which propagated a boycott against Elsevier, one of the four very large international publishing houses. The initiator, the mathematician W.T. Gowers, demanded farreaching changes of the modes of operation of the publishers and of their price policies: within a few months he collected about 13,000 signatures for this declaration (Schuh 2012). In this as in earlier proclamations, Elsevier and other large STM publishers are denounced as "greedy capitalists", which do not give a damn about the communication needs of science. Radical counter-measures are proposed now. A growing number of scientists want to get rid altogether of commercial publishing houses and substitute them by self-organized and publicly financed open access publications.

Looking at the other end of the spectrum, many publications in the social sciences and humanities are often issued by small publishing houses which operate only on a national market. Academics from these fields grumble that they meanwhile have to do most of the production process of a book publication themselves, delivering a print-ready copy to the publisher. Despite this relocation of unpaid work from publishers to authors, social scientists and scholars from the humanities fear that more

\footnotetext{
1 We cannot deal here with academies or scientific associations as publishers of scientific literature, and with university presses insofar as they are non-profit organizations - which is not always the case. A closer look at scientific associations reveals in most cases that their publishing activities nowadays are undertaken as if they were business firms; and non-profit university presses have much in common with commercial smaller academic publishers, with the gradual difference that the former must earn only so much money that costs are covered.
} 
and more of their publishers might be forced to give up sooner or later because the number of copies sold of most of their books is steadily declining. Hence, many academics in these fields also start to think about non-profit open access publications, but for quite different reasons than their colleagues in STM fields.

This looks like two radically different worlds of academic publishing - excessive profits in one, not enough in the other - where nevertheless the same conclusion is reached: self-organized open access publishing as the only solution of the problems perceived. However, we will not discuss the potential of open access publishing here. There is quite a debate about it going on, with strongly diverging views (Hanekop and Wittke 2006: 221-231, 2007: 209-219; Rowlands and Nicholas 2006; Park and Qin 2007; UNESCO 2007; Jochum 2009; Brintzinger 2010; Taubert $(\leftarrow$ p. 188) 2010). Whether some kind of open access will be established on a broad range in the future remains to be seen. At the moment, our concern will be the two worlds as we have them now, and most probable will have for quite some time.

Surprisingly, beyond some rather superficial impressions, in science studies little is known about how academic publishers work - in particular, how markets for books and journals look like, how publication decisions are taken, and how the interplay with the scientific community is arranged. ${ }^{2}$ These are the main questions we will address in this article, with a focus on the relation between economic considerations of publishers, on the one hand, and the requirements of scientific communication, on the other (Schimank and Volkmann 2012).

Our empirical data were collected and analyzed in a research project where we investigated practices of decision-making in academic publishing houses. ${ }^{3} \mathrm{We}$ conducted qualitative expert interviews with editors and publishers of five chemistry publishing houses and 12 German publishers of social science literature, along with additional interviews with some librarians and journal editors. In this article, we

\footnotetext{
2 There is only one detailed study of the editorial decision-making of academic publishers, conducted by Walter Powell (1985) quite some time ago. Meanwhile many things have changed, as the study of Patricia Thornton (2004) shows. For a general overview of recent changes in academic publishing in the USA and Great Britain, see Thompson (2005).

3 The project was funded by the Deutsche Forschungsgemeinschaft-project title: "Verlegerisches Entscheidungshandeln zwischen wirtschaftlicher und wissenschaftlicher Logik: Die Wissenschaftsverlage der deutschen Soziologie und Chemie", (SCHI 553/8).
} 
mainly deal with two in-depth case studies. One is a global STM publishing house where we focused on chemistry literature; the other case is a German language publisher of sociological literature. We are not interested in individual characteristics of both cases but in the two types of academic publishing they represent. The STM publisher stands for a worldwide hegemonic business approach whereas the sociology publisher is an example of a nationally-bound traditional business approach in the field of social science and humanities literature. Especially in comparison, these two publishing houses give a graphic picture of the different situations, risks and challenges, opportunities and limitations of the two worlds of academic publishing. Since the sociological knowledge about this topic is still very limited, we do not apply one specific theoretical perspective to it but use a heuristic analytical framework which assembles components from various perspectives - especially from the "new economic sociology," from organization studies, and from science studies - and which is open for new empirical aspects. In a brief preview we can present our framework as a sequence of four analytical steps which use similar ideas and concepts as the "general theory of strategic action fields" recently outlined by Neil Fligstein and Doug McAdam (2011):

- At the center of our framework are publication decisions in academic publishing houses. A first step to understand these decisions investigates the contexts of decisionmaking. Here we highlight, on the one hand, the market in which a publishing house operates, as Fligstein/McAdam would say, as a "strategic action field" with "incumbents" and "challengers." On the other hand, the relative market position of our investigated cases in this field corresponds to $(\leftarrow$ p. 189) certain of their organizational structures. From these two inter-related contexts - external market and internal structure_-important decision premises arise.

- In a second step, the decision-making itself is taken into account. Here we emphasize the interplay between those who are organizationally responsible to make publication decisions on behalf of a publishing house and those scientists to whom important parts of this decision-making are delegated. In these interactions between organizational representatives and scientists, the former must use what Fligstein (2001) calls "social skill”, with regard to the reliable cooptation of the latter.

- With these two steps we arrive at an understanding of basic features of 
publication decisions which characterize the respective publisher's business approach. A third step compares the outcomes of these decisions - the book and journal production of publishing houses - with crucial communication requirements of science and asks whether these are fulfilled. This aspect is missing in the approach of Fligstein/McAdam, but here we can rely on results from science studies.

- Up to this point, we have characterized the markets in which our publishing houses operate and their relationship to the scientific communities as stable “institutional settlements,", to refer again to Fligstein/McAdam. However, certain "exogenous shocks" and "field ruptures" have led to an "onset of contention." This current "field crisis" which we study in our fourth analytical step may bring about a new 'settlement"; however, at present nobody is able to make a safe prediction how it will look like.

Along these lines, the first two sections of this article present the two types of academic publishing houses with their settled business approaches which were quite stable for some time: first the chemistry, secondly the sociology publisher. Stability meant not only that publishers earned money according to their profit aspirations but also that the communication requirements of science were sufficiently met. In the third section, we will point out the instabilities that have begun to arise which may sooner or later erode the former fit of profit-making and scientific communication.

\section{Chemistry}

Chemistry, together with physics and biology, emerged in the 19th century as one of the three core disciplines of the natural sciences. Today, chemistry is one of the largest scientific disciplines - much larger than sociology, the other discipline we will take a look at. Whereas - to give just this number - the American Chemical Society has about 164,000 members, the American Sociological Association has $14,000 .{ }^{4}$ Another indicator of the large size of chemistry as a scientific discipline is

\footnotetext{
4 From the homepages of the American Chemical Society (http://portal.acs.org/portal/acs/corg/content? $\mathrm{nfpb}=$ true\&_pageLabel=PP_TRANSITIONMAIN\&node_id=225\&use_sec=false \&sec_url_var=region $1 \&$ uuid=30b469bc-47bb-4811-9a10-22d96faba795 visited 2013, Jan. 8) and the American Sociological Association (http://www.asanet.org/about/about_asa.cfm visited 2013, Jan. 8). In Germany there is roughly the same relation of the number of members of the Gesellschaft Deutscher Chemiker (about 30,000) and the
} 
( $\leftarrow$ p. 190) that in 2008 there were 114,206 publications in chemistry worldwide, which amounts to no less than 11.5 percent of all scientific publications (UNESCO Science Report 2010: 10/11). On the organizational level, in Germany there exist about 80 universities with chemistry departments or chemical institutes, and in the USA chemistry is established at more than 800 universities. ${ }^{5}$ In addition to academic research, the chemical industry is very research-intensive; in Germany the R\&D investment of its world-leading chemical corporations amounted to roundabout 3,500 million Euros for the year 2010 (FuE-Datenreport 2012: 9).

These few numbers must suffice to demonstrate that there is a large worldwide market for chemistry publications. We will focus our attention here on journals as the central type of research front publications in chemistry. Even if these journals are bought almost exclusively by libraries of universities, research institutes, and research departments of chemical firms, there are several thousands of these very reliable buyers worldwide; and many of these journals appear on a weekly basis and are very voluminous, with a huge number of articles, and up to 19,000 pages each year in one of the largest, the Journal of the American Chemical Society. Furthermore, this market will continue to expand, not the least as a consequence of the growing university sector of emerging countries such as China or India.

A large and global market, combined with the above-mentioned journal characteristics rules out small publishers in chemistry. The capital expenditure of the production and distribution process is much too high for small firms. The publisher has to provide a highly efficient technical infrastructure which can only be installed for a mass production of large numbers of different journals and books. ${ }^{6}$ In the last twenty years, the "digital age" (Thompson 2005) has required massive additional investments. Thus, on the one hand, financial needs are enormous and can only be met by large organizations; on the other, big publishing houses are able to realize massive economies of scale based on a standardization of organizational processes. An interviewee states:

\footnotetext{
Deutsche Gesellschaft für Soziologie (about 2,400).

${ }^{5}$ Own counting on the basis of http://www.chemlin.de/chemie/universitaeten.htm visited 2012, Dec. 11.

6 This is true even if the publishing house outsources the printing and mail distribution of journals and books.
} 
The whole production process, everything is standardized because otherwise you wouldn't be able to manage all that, the print version and then, in addition, the electronic version - not technologically, and it would be too expensive, too $(1: 67){ }^{7}$

Until the 1960s, a considerable number of national medium-sized publishers in chemistry all over the world still existed. Then a process of concentration began, and nowadays the overall global field of STM publishers is dominated by no more than four very large corporations - Elsevier, Springer, Wiley, and Taylor \& Francis (Dewatripont et al. 2007: 404). Each of these publishers serves all fields of STM, and each one's output covers more than 1,500 journals and up to 6,500 books each year. The three largest publishers together have a market share of more than $40 \%$ of all journals (Schuh 2012). They are "incumbents" which clearly dominate the field, $(\leftarrow$ p. 191) without any "challengers" (Fligstein and McAdam 2011: 5/6) in sight. There still exist some smaller STM publishers, for example, the German firms Thieme or de Gruyter. But these publishers operate in niches and sell a rather limited number of journals and books per discipline. As a representative from one of these firms frankly stated, their further existence relies on the goodwill of the big players: If one of them gets interested in the products of a small publisher, the latter is without a chance to resist a take-over (3:53).

The case we will take a closer look at is one of these four "incumbents." founded in the 19th century and gradually grew as an STM publishing house. During the period of concentration of the field it bought a number of other publishers. Its publishing program as well as its sales and profits have grown steadily for a long time. It perceives itself now as an already excellent place for the publication of scientific findings whose future key task is to make available the manifold possibilities of digitalization to further speed up the distribution of scientific knowledge. Its ambition - with regard to STM in general, and chemistry in particular - is to run as many of the main journals and important book series as possible. Instead

\footnotetext{
7 All quotes are translated by ourselves.

8 In the following, we have to keep the descriptive information on the case somewhat vague at certain points so that our informants' anonymity is protected.
} 
of sharpening the organizational identity by a distinct substantial profile of the publishing program - for instance, with regard to particular sub-fields of science extensive and intensive growth is the imperative. The latter means that the size of journals or the number of titles in book series has to increase further. Extensive growth consists of the establishment of new journals and book series in sub-fields which were not represented in the publishing program before, or of the acquisition of book series or journals from other publishers, or even of taking over other publishers as a whole. One interviewee from this publisher underlines this policy:

... you have to look at the size. The house publishes more than 1,500 journals and at the moment up to 5,000 books in one year but the numbers grow $(9: 17)$.

The organizational logic pursued is to become the largest, or the fastest-growing, scientific publisher. However, all of the big four STM publishers have the same ambition and, as a consequence, compete with each other. They all try to increase the number of their journals and book series and the impact factor of their journals. Thus, further growth based on a self-understanding of a "catch-all" STM publishing house is their common business approach.

As a consequence of this aggressive growth strategy pursued in a growing market and the high profits earned in this way, each one of these very large companies has become an object of financial speculations. Elsevier, as the largest, made about 7 billion Euro sales in its best years, and more than 30\% profits (Arnold and Cohn 2012: 828; Schuh 2012); and Springer whose profits were of a similar dimension was sold by its former owners to an investment fund in 2003 and re-sold to another fund in 2009; in 2013 it was re-sold again for a very good price because it had been and promised to be in future a highly lucrative source of profits (http://www. boersenblatt.net/626143/ - visited 2013, Oct. 11). This kind of ownership has most $(\leftarrow$ p. 192) likely increased the pressure for profits even more - more specifically, for short- term profits as in many other branches of industry which have become subjected to " financial market capitalism" (Windolf 2005) with its shareholder value orientation. But what does it mean for the daily work of those involved in the running of chemistry journals and book series that this year, say, a 15\% increase of overall organizational profits or of the chemistry sub-unit as a profit center has to be achieved? The crucial organizational role to be looked at for the translation of such 
ambitious profit goals into the journal and book production is the " planner"' (1:223). This is how some of the editors of the big STM publishers now call themselves - and this change of name expresses an ongoing change of the whole publishing profession, not least with respect to a stronger emphasis on economic considerations (Hömberg 2010: 197-203).

A marked shift in the range of duties is occurring, compared to the traditional editor whose central tasks are to select manuscripts for publication and then to work on the selected manuscripts until they are ready for publication. In contrast, "planners" or program managers in these STM publishing houses are now doing very different things. ${ }^{9}$ As one of them explains:

You have to judge the quality and things like that, that's obvious. But as I said, I don't read it myself... (1:228).

There are basically two components of the program manager's job which are critical for the publisher's successful profit-making. The first consists of the strategic task to conceive an attractive program of journals and books - in the words of another program manager:

I take care that contents are available. I have to take care that contents are interesting and relevant, that they will be used (2:60).

Strategic decisions are, among others, decisions to establish new journals or book series or to buy or sell them, with the general aim to have as many "flagships" (1:52) - high-impact journals or book series - in the portfolio as possible. Secondly, the program managers are responsible for the day-to-day management of the journal and book production. This boils down to a control of the workflow so that journals and books appear in time and quality standards are maintained. The workflow is characterized by a high degree of formalization and division of labor because standardized and specialized practices rule the parallel production of thousands of journals and books.

Both with respect to strategic decisions as well as to the daily workflow, the program manager is highly dependent upon scientists who are willing to engage

\footnotetext{
${ }^{9}$ In the following, we use the term program manager for a staff member of a publishing house who makes publishing decisions - whether it is a traditional editor or a new "planner" or even the publisher himself.
} 
themselves as voluntary and unpaid contributors to the organizational processes. This dependency results from the program manager's ignorance of the actual state of the art of chemistry in its diverse fields and of each field's future prospects. Even if the program manager is a chemist by training, which is often the case, his active $(\leftarrow \mathbf{p}$. 193) participation in research is over for a long time; and in this large discipline, even as an active participant one has only a rather limited experience in a few specialties. Thus, no single person has a sufficiently detailed overview of chemistry as a whole; this overview can only be reached by a bundling of the scattered knowledge of many specialists.

With respect to the strategic task of program managers, this means that they have to rely on continual informational input from a wide network of knowledgeable chemists. One part of this network are strong ties of regular and formalized contacts - especially with scientists who work as journal or series editors. Still, these strong ties alone would be insufficient because sooner or later they transmit the same messages again and again. So a wider range of weak, irregular and informal ties has to be added from which additional and different information can be gathered, such as casual talks at conferences. ${ }^{10}$

The overall network of strong and weak ties is also needed for the day-to-day production of publications. Here, scientific quality control of each of the manuscripts is essential. With the recruitment of journal, series, and book editors, the publisher decides to which scientists this quality control is delegated. Most important is the organizational cooptation of reliable and competent editors-in- chief. To make the right appointments to these key editorial roles, a program manager has to have a good overview of the scientific community.

The daily work of journal editors ranges from the recruitment of numerous peer reviewers of manuscripts up to the decisions of an editorial board based on these peerreviews. Here, the program manager has to bring all these non-employees to contribute in a reliable manner to the organizational production process. What the program manager can offer to journal, series, and book editors is mainly the reputation they attain in their scientific community for doing this work - and the higher the reputation of a journal or book series, in particular, or of the publishing house in general, the higher the reputational gain of editors, and the more attractive

\footnotetext{
${ }^{10}$ For these general characteristics of strong and weak ties, see Granovetter (1973).
} 
it becomes for scientists to do this work. ${ }^{11}$

Looking a bit more closely at the production of journals, strategically, the editorin-chief of a journal defines its thematic profile and its development in accordance with changing research topics of the respective field. As a program manager stated unequivocally: "The journal editor is responsible for the content of the journal" (1:20). But much more time-consuming is that the editor-in-chief is in charge of the overall organization of the workflow. The immense amount of manuscripts which have to be handled by highly reputed journals and the high frequency of new issues necessitate a high standardization and reliability of the publication process. Here the main task of the program manager is to "take care" (1:225) of the journal and its editors. This friendly wording means that he has to make sure that all journals in his portfolio appear regularly and in time and with a sufficient number of articles - and $(\leftarrow$ p. 194) to achieve this without any compromises of scientific quality. Even more, ongoing quality improvement combined with quantitative growth are the benchmark:

We want our journals to grow, but the quality of course has to be high. These two criteria belong together $(1: 254)$.

The combination of perpetual surveillance of and pressure on journal editors by the program manager requires considerable "social skill" in the sense of "engaging others' (Fligstein and McAdam 2011: 7) for the organizational goals. The program manager's ability to achieve this has been strongly increased by the introduction of online editorial management systems (Taubert 2012). With such a system the program manager can monitor in real time the processing of manuscripts including the email exchanges. If a journal editor lags behind with the processing of manuscripts, the program manager notices this very soon - and the journal editor knows that this is the case. In extreme cases of chronic delay, the program manager has to dismiss the journal editor and has to find another one. What the program manager still cannot do is to assess the scientific quality of articles. However, beyond subscription numbers and impact factors of journals, a program manager now has additional opportunities of market observation - among others, as one of them points

\footnotetext{
11 A few journals are run by in-house editors paid by the publisher. But this is the exception. The critical weakness of this model is that the in-house editor is no longer a practicing researcher and so loses contact with the research front quite soon. Thus, he also depends upon scientists as knowledgeable insiders.
} 
out, “... I can take a look at the downloads ..." (1:80). By offering all products journals as well as books - in electronic form on the publisher's online platform a detailed and real time user analysis becomes possible. With regard to journals, program managers can check not only how often particular articles were downloaded but also how often denials occurred. The latter show that a scientist tried to download something but his university library did not have the access rights. A documentation of such gaps in a library's catalogue is useful information for the next sales negotiations.

Digitalization has reinforced the described role-understanding of program managers as translators of economic imperatives in an even more profound way. Until a few years ago, STM publishers sold single books and journals to each library. But as one interviewee makes very clear:

... the business models ... are changing, going away from the single product or a single journal, even more a single book, and towards packages which are offered to the libraries $(2: 58)$.

Nowadays, large STM publishers sell digital product packages or annual packages for each discipline - or the whole program (Schuh 2012). An interviewee states: “... we still sell single journals but basically we sell the whole content ..." (1:253). So the access grant to its portfolio - and in effect to its online platform - has become the key product of our case. Consequently, it is proclaimed: "Our heart is the platform!'” (9:55) With this package model the quantity of the publishing program has become much more important than before:

It's the mass! Of course, it's the mass being important! You have to offer very much and you can't be too small (9:50).

This implies that there is no longer an economic calculation of single products. A program manager explains: $(\leftarrow$ p. 195) Earlier we had to do calculations and stuff like that, but nobody does something like that nowadays any longer. Because the electronic products are sold as packages ... (1:63).

It is likely that these package deals allow for a relaxation of quality standards. Some products of lower quality may be sold as part of a package.

All this leads to the general question how the described characteristics of the 
products and production processes of STM publishers such as our case correspond to the communication demands of the scientific community of chemists? ${ }^{12}$ Chemistry is a large-scale "normal science", (Kuhn 1962) whose knowledge production mostly is a cumulative "puzzle solving" which implies low risk and no fundamental disagreements. Under these conditions, universal peer review provides for a reliable selection of publications according to agreed-upon disciplinary quality standards. Thus, a highly standardized peer reviewed journal article is the prevailing and epistemologically adequate type of publication. Furthermore, journals are the best type of publications to achieve a fast and "widest possible distribution" (Vries 2007: 198) of new knowledge. In addition, if the spectrum of journals is well differentiated with regard to thematic fields as well as reputation, as is the case in chemistry, researchers looking for highly specialized new knowledge quickly find what they are searching despite very limited attention spans.

These communication demands of chemistry can be generalized as three publication requirements of science:

- Distribution: Ideally, especially the research front shall be provided with unlimited publication opportunities to make sure that each relevant research result becomes available as quickly as possible to as many other interested researchers as possible (Gläser and Lange 2007: 439).

- Selection: However, not all publication offers shall be chosen but only those which reach a minimum level of quality. Academic publishing needs a kind of "knowledge control"' (Parsons 1989: 14-16) which is secured by peer review.

- Structuring: In addition to selection, what is actually published shall be ordered in a transparent manner so that readers interested in specific new research results find them as easily as possible within a huge universe of publications (Luhmann 1970; 1990: 244-251; Nicholas et al. 2005: 213-214). The two most relevant dimensions of structuring are, firstly, according to thematic fields and, secondly, according to the level of quality as indicated by an author's reputation (Morris

\footnotetext{
12 For epistemic characteristics and the complementary communication requirements of chemistry-as well as sociology to which we will turn later-see the relevant observations in Whitley (1984), Fuchs (1992: 143-215), Clemens et al. (1995), Becher and Towler (2001), DFG (2005), Braun (2006), Wissenschaftsrat (2008: 358-361, 444-446), Hahn (2009), Mü nch (2009), and Gläser (2010).
} 
To act according to these three requirements, publishers, on the one hand, have to avoid an over-restrictive limitation of publication opportunities because then they would not adequately fulfil their distribution function. However, on the other hand, they must also prevent a chaotic publication avalanche which would amount to an inadequate realization of their selection and structuring function.

Measured by these three requirements, the worldwide rapid dissemination of new results from the research front is achieved very well by large publishing houses which, first, with regard to products, offer a huge number of globally distributed specialized journals which appear with a high frequency, and secondly, with regard to the production process have standardized products, highly routinized work flows, economies of scale, a well-developed division of labor and, not to forget, the ability to mobilize the capital needed to establish and innovate permanently the necessary organizational and technical infrastructure. All these comparative advantages of large publishers are even enhanced by the new policy of selling electronic program packages. On top of that, digitalization has provided additional tools for scientists as readers to find the literature they need in a highly efficient way.

Up to this point it looks as if the business approach of large STM publishers and the "institutional settlement" of the field dominated by this approach fit quite well to the publication requirements of a discipline such as chemistry. ${ }^{14}$ Before we come to the weak spot of this arrangement we already alluded to at the beginning, however, we will shift our focus to the social sciences and humanities and their publishers by another case study.

\section{German Sociology}

13 Not surprisingly, these three requirements roughly correspond to the main functions attributed to publishing houses (Parsons 1989: 192; Lucius 2005; Blaschke 2010: 457-507). Some other functions mentioned in the literature can be subsumed to these three. In particular, permanent recording of publications is an extension of the distribution function, and certification of knowledge claims is an important result of the selection function.

14 To be sure, there is no kind of functionalist magic at work here. How this fit came into existence, and how much this is due to accidental circumstances is a question of its own we cannot answer here. 
Our second case is a traditional German publisher of sociology. The most striking difference between it and the large STM publisher is that the sociology publisher's market is not global but restricted to Germany and other German language countries - Austria and parts of Switzerland. Thus, this case is not representative of social science and humanities publishers in general. Indeed, there are English language publishers in these fields such as Routledge or Sage which are much more similar to STM publishers or even belong to one of these publishing houses. But in many countries we have publishers in the social sciences and humanities which serve only the national market. The huge difference of market size between the worldwide community of chemists served by the large STM publishers and the German language community of sociologists is the key to understand the very different business approach of the publisher of German sociological literature we now present.

News from the sociological research front is only partly communicated in journal articles; monographs and edited volumes are the other two important types of publications. The number of copies sold of German sociological books as well as the number of journal subscriptions is very small and has steadily declined during $(\leftarrow$ p. 197) the last decades. Some program managers with a long work experience still remember the late 1960s and early 1970s when, not only due to the student unrest of “1968," sociology for some years was a discipline with a high impact on public debates so that many sociology books, even with very special topics, easily sold several thousand copies. These golden days for German sociology publishers lasted just a few years. Nowadays, most books which belong to the research front literature do not sell more than 300 copies, often much less, and the most prominent journals each have less than 1,500 subscriptions; ${ }^{15}$ in addition, no more than about ten relevant sociological journals appear in Germany.

This small market nevertheless is served by quite a number of rather heterogeneous publishing houses, with more than a dozen being counted as important by the German sociological community. Most of them were founded after World War II. The majority of them are pure academic publishing houses. Some others - such as

\footnotetext{
15 Highly specialized journals, such as "Sport und Gesellschaft" dealing with sports, cover only the contribution margin. As a publisher told us: "At 250, 300 [subscriptions] it starts to work, if you charge a certain price level"' (9:862).
} 
Campus Verlag or Suhrkamp Verlag - are partly trade publishing houses. Only a few sociology publishers, such as Nomos or Beltz Juventa, belong to a larger publishing house, and only one - Springer VS - is part of a big STM publisher which is owned by investment funds. The majority of publishing houses of German sociology are managed by their owners.

A publishing house of German social science and humanities can be considered as large if it publishes more than 200 new books each year, as medium-sized if the number of new titles is within the range of 50 to 200, and as small if the yearly front list includes less than 50 books. Within this frame of reference, most of the relevant publishing houses of German sociology are medium-sized or small - and even more so if only sociology publications are counted. As a consequence, only the larger publishers such as transcript Verlag with its frontlist of 300 titles in total -including about 100 sociology books - or Campus Verlag, which publishes round about 140 new books annually, cover many areas of sociology, whereas the smaller ones such as Edition Sigma, which publishes only 30 new books per year, are thematically specialized. All in all, although there are considerable differences of economic and reputational standing as a "strategic action field," this market is not strongly dominated by very few or even one player.

Whereas STM publishers earn their money by selling journals as well as books, German publishers of sociology primarily depend on book sales. The dissemination of German sociology journals is only national. Most of them appear just four to six times a year with approximately 500 to 700 pages. Accordingly, the prices libraries or private subscriptors pay for subscriptions are low. Hence, sociology journals are important for the publishers only in terms of "social capital" (Bourdieu 1983: 190195), on the one hand, and "symbolic capital" (Bourdieu 1984: 22/23), on the other. As one program manager told us:

It's because of the networks and persons and so on. I would never underestimate this. Even if you have to contribute some 1,000 Euros for the foundation of a journal: It has brought us additional books $(4: 925) .(\leftarrow$ p. 198)

Nevertheless, not every German publishing house of sociology has journals in its publishing program, and even for those which publish journals this is no essential of their program. Therefore, it does not matter that our selected case is one of those publishers without journals because we will focus in the further analysis on the 
publication of books as the primary product of German sociology publishers. ${ }^{16}$

Our case is one of the established medium-sized German publishers of social sciences and humanities. Its yearly number of new publications has not changed during the past ten years. This publisher perceives itself explicitly as a publication place for research front literature:

We are the innovative publishing house trying to promote innovative sociological content, and not primarily the mainstream $(5: 228)$.

The publisher distinguishes itself from "dissertations publishers," on the one hand, which finance their books almost totally by printing cost subsidies from the authors: "With nothing but a subsidized publishing program you are not attractive"' (17:165). On the other hand, our case perceives itself as different from those publishers which rely on quantity and do not care for a distinct profile of their book program: "We are no book factory" (5:228). Our case is strongly concerned about the sharpening of its organizational identity. As one of the program managers remarks:

Otherwise it's getting difficult, I think. If you become exchangeable there's hardly any reason for someone to choose such a publishing house (6:708).

An organizational identity has to be presented to the outside to be perceived and confirmed by others, especially by readers and buyers but also by authors. For this reason, the publishing house must have enough books in its list that represent its specific profile:

Some titles you publish only for the profile, the so-called profile titles. Where you are glad not to lose too much. ... You must publish known names and major works, too, to generate attractiveness. So that you will remain attractive $(17: 165)$.

Series A really was planned as the flagship where we want to put in all our good things. That's for the profile, not for the profit (17:421).

So, even losing money with some of these "profile titles" is perceived as necessary

\footnotetext{
${ }^{16}$ Furthermore, the decision-making process and the workflow of the journal production in sociology are largely identical with the processes described for chemistry journals, just on a much smaller scale and much less standardized.
} 
to "remain attractive", for readers as well as authors with the entire publishing program.

This self-understanding shapes the general business approach of the publishing house and the specific publication decisions taken. Research front literature is about $60 \%$ of its book program. The remaining part includes textbooks as well as "public sociology", (Buroway 2005) titles for a wider audience beyond sociologists and their students. $(\leftarrow$ p. 199)

With regard to the economic side, for German academic publishers in general the publishing of research front books is not very risky in financial terms because printing cost subsidies paid by the authors, their institutes, or funding agencies are common. For instance, a research grant from the Deutsche Forschungsgemeinschaft (DFG), the most important German funding agency, includes money for publication costs. The publisher's argument for the necessity of cost subsidies is the rather small number of copies sold today:

We don't publish books if the number of copies is less than 200.... We start with 200 , but on average it's $350(6: 271)$.

Two reasons for the small number of copies sold are mentioned by the program manager:

I think the reason is an oversupply, and that the university libraries no longer buy everything $(6: 161)$.

Due to the small number of copies, nowadays the profits made from selling research literature to university libraries and a few individual scientists are only moderate but still safe. Even if flops occur from time to time, the losses are not large, because the cost subsidies cover a considerable part of the publication costs.

In contrast to research front literature, the publication of textbooks as well as of "public sociology" titles costs more and is financially more risky, but opens up the chance of much higher profits. Thus, good-selling textbooks and "public sociology" titles are the basis for a mixed calculation where they subsidize the publication of those research front books which are important for the image but economically less profitable or even unsuccessful. Hence, a program manager declares:

To concentrate oneself only on one field would not be intelligent for an 
academic publishing house (6:344).

To be sure, textbooks and "public sociology" titles should also fit to the profile of the publisher. In our case, they go along with research front literature to establish and maintain the specific organizational identity.

How is this business approach translated into the daily decision-making of the program managers? Each manuscript offered to this publisher passes through a threestep examination. If the manuscript, first of all, fits thematically with the current and future publishing program, the second step concerns the quality of content. Only if the program manager is convinced of the quality and gets interested in the book, the third step of calculating the economic feasibility will follow: "The decision to publish a book is never 'pure'; it always rests on a guess about the market for a book as well as on an appraisal of the book's merits"' (Powell 1985: 211).

With regard to research front literature, the main criterion of quality is the sociological "leap of knowledge"' (17:401):

It's difficult to describe what's meant by innovative strength. It can be a methodology, or a perspective. It can also be the manner by which different $(\leftarrow$ p. 200) fields are combined, which have never been connected before. Simply, new interesting perspectives on something (6:538).

Although there are additional criteria of quality, such as the coherent structure of the content, which refer to formal aspects, the decisive criterion - the "leap of knowledge" - clearly relates to the core of scientific knowledge production.

Compared to STM publishers it is striking that the program managers of social science publishers are confident that they are able to assess most manuscripts' scientific quality on their own. Only when they are uncertain about a book or book proposal they consult scientists who are experts of the respective thematic field. ${ }^{17}$ To assume to be able to judge many manuscripts without further advice requires that program managers are - and, according to their self-conception, have to be - social science generalists. Thus, as a rule they have studied sociology or a related social science discipline. Although some program managers of STM publishers have also

\footnotetext{
17 When they decide about the publication of dissertations, editors primarily take a look at the attached assessments of the reviewers before calculating the project.
} 
studied the discipline for whose journal and book program they are responsible, they would not dare to even interfere in the quality assessment of a manuscript by the scientific experts. This reflects the much higher degree of intra-disciplinary specialization and speed of scientific progress of chemistry where a generalist's knowledge from the times of study soon becomes obsolete, and even up-to-date specialists are often unable to judge scientific work done in another specialty of the discipline.

From the organizational point of view, a social science publisher counts on the disciplinary knowhow of its program managers. This makes the publishing house not only less dependent on scientists than STM publishers are. Even more important is that the organization can do without many formalized criteria of decision-making:

Yes, indeed, there are specified criteria for particular books, some qualitative, some quantitative criteria. That's no question. But all the criteria ... can't substitute this sense, this intuition $(5: 356)$.

Even more, formal criteria would actually stifle the program managers' "experience" (17:177) which ensures that the right decisions are taken. In addition to "experience," the program managers' qualifications include "economic mindfulness” (5:340). Program managers “... are always product managers” (17:683). For each publication they have to check the market chances by answering the question, “... who might be interested in this?" (17:228) Thus, the long-term strategy of the publishing house usually is not the result of a deliberate pursuit of a "business plan" but grows in an incremental manner out of the daily publication decisions made on the basis of personal judgment.

Up to this point we have highlighted the very strong position of the program managers of social science publishers as rather independent decision-makers within a quite loose organizational framework. However, the program managers' "social skill" also includes extensive personal networks with German sociologists. With regard to the necessity of such networks, there is basically no difference to STM publishing houses. An active networking is important for a German social science $(\leftarrow$ p. 201) publisher such as our case because many of the offered manuscripts of 
research literature “'... arrive via established networks"' (6:468). ${ }^{18}$ Thus, most of the new contacts, especially to younger sociologists, are the result of such histories of ongoing contacts with persons and institutes. Furthermore, these networks are the primary source of information about "hot" topics of current and future sociological debates. As a program manager remarks about scientists as book series' editors:

Therefore, the series' editors are extremely important. Because they are close to the developments, they see what's going on, what's coming up, and where you have to stay on the ball (6:598).

Finally, it is important that the networks include sociologists with a high reputation in the community who appear as authors and series' editors. To attract and commit "big names" of the sociological community, the program managers of our case sometimes even make concessions with regard to quality of manuscripts because the visibility and reputation gained by titles from authors with high reputation is one important way to attract good authors in the future.

Thus, social science publishers, too, co-opt scientists as series' editors; ${ }^{19}$ and then it is up to them to decide whether a manuscript will be published in the series:

It's the essential function of series' editors to give a professional opinion on the quality of the manuscripts, which they are bringing in. ... That's ... a kind of quality assurance, and you rely upon this expertise (6:405).

This statement could have been made by an STM publisher. However, in sociology the quality check of research front literature is only partly delegated to the discipline. Neither are all of the decisions about the publication of manuscripts made by sociologists; on the contrary, the majority of these decisions are made without an involvement of the scientific community. Nor can the series' editors who indeed take publication decisions do what they want. First of all, the program manager's general sociological knowledgeability allows him to participate in the decisions about the thematic orientation of the series. Secondly, he makes use of his "right of veto" (6:402) if specific decisions of series' editors do not fit with his own understanding

\footnotetext{
${ }^{18}$ In this respect, a publisher whose main products are books instead of journals depends even more upon personal networks.

19 And also as journal editors if journals belong to the publisher's program.
} 
of the thematic orientation or if he anticipates financial losses.

To sum up, this business approach relies on moderate profits which are, with regard to research front literature, mostly quite secure as a consequence of subsidies. There is no strong competition between publishers because each of them attempts to carve out a somewhat unique organizational identity based on thematic fields or scientific schools; until quite recently, none of them has pursued an aggressive growth strategy detrimental to the interests of the others. Finally, there is only a weak push to increase organizational efficiency. Profit pressures from investors do not exist, and owners or silent partners have no excessive profit aspirations, not the least because many of them, as well as their program managers, understand themselves as "servants of science." Frank Schwoerer (Schwoerer 1998: $12-$ our $(\leftarrow$ p. 202)

translation), founder of Campus Verlag, looked back in a mixture of pathos and irony:

I understood us, the publishing people, as the ground crew of the disciplinary

Weltgeist. ${ }^{20}$

But even if considerations for efficiency become stronger as a consequence of the necessity to reduce costs, opportunities to increase efficiency are limited simply because these publishing houses are small so that cost-saving standardizations do not make much sense and economies of scale are almost impossible. If it becomes unavoidable, it is easier to save costs by shifting even more unpaid work on the authors of books, or to demand still higher subsidies.

Certain communication requirements of sociology are served quite well by this “'institutional settlement", of the field. ${ }^{21}$ As already stated, journals with peer review are not at all as central as in chemistry. From 2000 until 2005, only about one third of all publications of German sociologists were journal articles, and only one third of them - one out of nine publications - had been subjected to a peer review; about half of all publications were articles in edited volumes and roughly one tenth were monographs (Wissenschaftsrat 2008: 445). Thus, books - mainly edited volumes are the most frequent type of publication, and they are almost never peer- reviewed. ${ }^{22}$

\footnotetext{
${ }^{20}$ For similar statements, see Wulf D. von Lucius (2005: 37) and Blaschke's (2010: 371-385) study of publishers of history.

21 See again the literature cited in footnote 13.

22 Different from the practice of most of the well-reputed British and American social science publishers.
} 
Still, to categorize this neglect of peer review merely as a lack of quality $\operatorname{control}^{23}$ is far too simple. In contrast to a discipline such as chemistry, sociology is paradigmatically divided up to the point that even disciplinary basics are controversial. Therefore, the peer review in journals is often rather destructive than constructive. As a consequence, monographs and articles in edited volumes play an important role to secure publication places for all kinds of sociological perspectives in general, and unorthodox approaches, in particular. ${ }^{24}$

The plural landscape of publishers also is a second factor which offers opportunities for publications from all the diverse paradigmatic orientations and schools of sociology. Thus, the fact that besides our case quite a number of others which are not larger or even smaller exist, and that each of these publishers strives for a distinct profile of its own with regard to sociological topics and approaches is perhaps no necessary condition but surely advantageous to maintain the multiparadigmatic "live and let live" of the discipline. Hence, with regard to the selection function, a one-sided over-selectivity is avoided. In addition, this shape of the organizational field also serves the structuring function both horizontally and vertically. Everybody knows what kind of approaches and topics as well as what kind of authors are associated with a particular publisher. To publish at the right place remains important for one's own visibility and reputation. Finally, with $(\leftarrow$ p. 203) respect to the distribution function, the possibilities of these smaller publishers are still sufficient. This is the case because the audience of the German sociologists' knowledge production is to a strong degree nationally bound and the pace of the production of new knowledge is much slower than in chemistry.

The national reference of considerable parts of German sociology should not only be attributed to an inability or unwillingness of German sociologists to enter the international stage. ${ }^{25}$ Two further reasons have to be taken into account. First of all, if a national community of sociological specialists in some sub-field of the discipline - for instance, political sociology - is large enough, it can be quite appropriate if, besides a participation in international debates, the national language such as German

23 As an expert commission of the German Wissenschaftsrat (2008: 445/446) did.

${ }^{24}$ It is true that the price to be paid for this diversity is under-selectivity with regard to quality. In addition, the access to publication subsidies is not always correlated with scientific quality.

25 As, again, the Wissenschaftsrat's (2008: 444/445) expert commission suggested. 
is used, too. That does not mean that German political sociologists have no international publications but that at least a significant part of their publications is written in their national language.

Secondly, and more important, sociology often deals with topics which have only a national interest (Münch 2009: 72). In contrast to research topics in chemistry, which are not bounded in space so that English nowadays is the "lingua franca" of this discipline, many sociological topics, even when they are conceived of in a general theoretical framework, refer with regard to particular empirical phenomena and questions to country specificities. To continue the example of political sociology, the general question for the societal preconditions of stable democracies is surely of worldwide interest; but as soon as this question is empirically specified to certain institutional peculiarities of the German political system such as federalism, election rules, the party system, or political culture, the international interest declines rapidly, and for good reasons. The same is true for many other relevant sociological questions, and this explains why even rather small national sociological communities as in the Netherlands or in Norway are not at all totally internationalized. ${ }^{26}$ Thus, as long as the attention-span of the discipline remains nationally bounded for many topics and the critical mass of researchers for a national specialist community exists, it still makes sense in cognitive as well as in reputational terms to publish in German which presupposes that there exist publishing houses devoted to the German market. Since large international publishers would not be interested to build up a special book and journal production in German language, this market remains a niche for small and medium-sized national publishers such as our case.

The overall picture of the publishers of German language sociology up to this point gives the impression that the book and journal production, despite some limitations, in important respects accords to the communication requirements of German sociology. But, as for STM disciplines such as chemistry, this is not the whole story.

$(\leftarrow$ p. 204)

\footnotetext{
${ }^{26}$ A casual look at the publication lists on the websites of sociology professors at Norwegian and Dutch universities shows that most of them still publish a considerable part of their work in their national language, and with national publishing houses. So even in these small countries a national language publication reaches a critical mass of readers within and beyond the sociological community.
} 


\section{Destabilizing Forces}

We now take a look at recent developments in both fields of academic publishing which have brought about "exogenous shocks" as well as by endogenous "field ruptures"' (Fligstein and McAdam 2011: 8/9). To start with the large STM publishers, they have to beware of becoming victims of their own market dominance which has resulted in an enormous economic success which is backed by an ever-growing supply of manuscripts. The overall worldwide volume of STM publications has grown steadily over the past 25 years, depending on the database used, by almost 3 up to $14 \%$ each year; the growth rate of the number of peer- reviewed journals in all fields of science is reported as about $3 \%$, with the number of pages of many of these journals also increasing (Larsen and von Ins 2010: 585, 594). Although the growth of scientific manpower may have stagnated in some Western countries, especially emerging countries such as China, India or Brazil build up their national science systems at a very fast pace. In addition, new governance regimes of national science systems have increased the pressure to publish on scientists because numbers of publications, especially in high-impact journals, have become an important indicator in evaluations (Schimank 2010). Thus, a growing number of journals corresponds with a growing number of manuscripts submitted; and because all in all the work of the program managers - together with the other organizational units - has been quite successful in terms of strategy as well as day-to-day management, the large STM publishers, such as our case, have been able to make very good profits from these developments. Instead of satisfying owners and investors, however, this success has only initiated higher and more short-term profit aspirations.

The publishers' main reaction to this intensified pressure for profits from its investors has been a massive increase of journal prices during the last 20 years which brought about the so-called "serials crisis" - that, of course, is the perspective of the libraries on the publishers' high profits - starting in the 1990s (Tananbaum 2003; Thompson 2005: 99-102; Haucap et al. 2005; Greco et al. 2006, 2007; Hanekop and Wittke 2006: 216-218, 2007: 207/208; Steele et al. 2006: 287; Brintzinger 2010: 333-335). Since the mid 1980s until 2005 the average price of scientific journals increased by the factor six; and this increase has not stopped until today. The highest average price per title in the year 2009, 3,690 US \$, was for chemistry journals; as a comparison, the average price for a sociology journal was 
only 615 US \$ (Boni 2010: 294/295). ${ }^{27}$ Contrary to what publishers say, librarians and scientists insist that these price increases have even been intensified by the abovedescribed "bundling', of electronic journals or books in packages because libraries are forced to buy many journals they are not interested in to get the ones they want (Schuh 2012; Arnold and Cohn 2012: 831). Elsevier sells its "Complete Collection", for periods of three or five years with in-built price increases which exceed inflation rates. $(\leftarrow$ p. 205) These enormous price increases do not originate from an increase of journal size or from quality improvements. Instead, they show that the publishers act as rigorous profit-seekers which exploit the fact that the scientific libraries are under strong pressure from their scientists who demand that access to all the important journals is locally available. In the words of a librarian:

That's a question of the price elasticity of demand. If you really want and must have something, then you are in a weak negotiating position. That's our problem, and the publishers know about it (2:385).

Thus, libraries very often have had no exit option and, as a consequence, have had to pay almost any price demanded from them - until, in the final end and despite all protests from scientists, more and more university libraries had to start cancelling even important journal subscriptions due to lack of money (Boni 2010: 295).

Obviously, especially the distribution function takes serious harm in its social dimension. A program manager realizes:

The question is, how easy it is for a scientist to have access, access is very important (1:214).

In fact, those scientists whose universities or institutes can no longer afford to buy all the journals and book series needed for research are partly excluded from the research front as readers of scientific literature; at least their access to it is hampered which gives them a competitive disadvantage as producers of new knowledge and, further on, as authors of new publications.

The consequences of these developments actually reach beyond the respective STM disciplines such as chemistry - to pick up again the "bundling", policy of

\footnotetext{
27 For example, for the subscription of the Zeitschrift für Soziologie-one of the two German journals of sociology with the highest reputation-libraries actually pay only 136 Euros per year.
} 
Elsevier: "Because of bundling, ever larger portions of library budgets are locked into Elsevier contracts, budgetary pressures force the cancellation of titles from smaller publishers, and funds for new subscriptions disappear', (Arnold and Cohn 2012: 831). In other words, other types of publications such as books and other, smaller publishers are affected - and both effects come together as a growing problem for the social sciences and humanities, as a librarian remarks:

The serials crisis is not just a price increase for the natural sciences which annoys natural scientists, but it is a structural distortion of the library system as a whole with consequences reaching into the humanities and social sciences $(3: 68)$.

This STM-wide "serials crisis" still exists today as a major "field crisis" (Fligstein and McAdam 2011: 15-19). Some years ago libraries started to offer open access platforms for in-house publications or repositories for a broader or even worldwide authorship. Besides, librarians as well as funding agencies such as the DFG in Germany now appeal to scientists to publish in open access journals; and quite a number of such journals have been initiated in several scientific fields by scientists themselves or by libraries (Mruck and Mey 2008). In this respect, digitalization has provided libraries and scientists with an exit option they did not have before. However, although most scientists in all disciplines as readers clearly sympathize with the open access idea, as authors they still prefer to publish in the established $(\leftarrow$ p. 206) journals because their impact factor is much higher (DFG 2005: 39-52). By now only a small number of open access journals have reached a sufficient reputation to make them an attractive place for publication of one's work. Whether this is just a matter of time, and what will eventually come out of the present confrontation of the large STM publishers such as our case with libraries and scientists remains to be seen.

At least the publishing houses had to realize that they are not only under pressure from their investors but that a counter-pressure exists which cannot be simply ignored. Publishing houses have to be careful not to enrage scientists beyond acertain point because then their willingness to contribute essential editorial and reviewing work without pay might drop dramatically. Until now, STM publishers could rely on the threat that they easily find someone else who - because of the reputation - readily waits to become an editor or editor-in-chief of a highly reputed journal; thus there was no plausible threat of exit by an editor. This may change with enough collective 
unrest in the scientific community. When more and more scientists are becoming profoundly dissatisfied with the way how the large STM publishers handle their journals, whoever still dares to work as an editor for one of these publishers might be blamed by his or her peers. In turn, whoever moves from such an editorial post to a self-organized open access journal might get applause. Since editors are important persons to commit reviewers, with their stay or retreat a journal's fate may be sealed.

Thus, in this "strategic action field" there may arise "challengers" of the "incumbents" not from among their economic competitors but from the side of their "customers" in the scientific community. Three stylized scenarios of future developments seem to be possible. First, enough scientists refuse to collaborate with the large STM publishers as editors, reviewers, and authors, and in cooperation with university libraries they establish a non-profit self-organized open access publication system which replaces the commercial publishing houses; secondly, the collective protest of scientists is at least strong enough to force the publishers to make substantial concessions, especially to lower journal prices considerably; and thirdly, it turns out again that the protest is not sustainable and the publishers are able to continue their policy of price increases. If the first scenario will come true, the existing STM publishers will disappear; and if the third scenario will happen, it remains to be seen whether STM publishers will really damage their business approach by demanding prices which almost no library can pay any longer. Their well-considered long-term interests direct them toward the second scenario; but, as we know, actors under short-term pressures are not always willing and able to do what is best for them in the long run.

Compared to the "strategic action field" of global STM publishers, the field of German sociology publishers looks basically sleepy, at least on the surface. During the last decades no dramatic changes have happened. Still, several weak points which are connected to each other as a result of gradual change have recently become visible and may soon become serious problems.

To begin with, these publishing houses can no longer ignore the "exogenous shock" of digitalization because scientists as readers - and to a lesser degree as authors, too - more and more demand some of the additional services it offers. The

$(\leftarrow$ p. 207) 
distribution and the structuring function could be much improved by the technical possibilities of digitalization as we showed for the STM publishers. But to cope with the challenges of the "digital age" costs a lot of money, as one of the publishers reflects upon:

That's a future business, a future industry, digital publishing. And you have to do it. This stresses our resources very much. Because we just have committed personnel and financial resources, which we must invest in the digital sector. There's no way out $(5: 256)$.

In contrast to our STM case, the German sociology publisher is still at the beginning of digitalization. As some others, this publisher offers e-books in addition to the print version and has begun to build up an electronic direct mailing system to generate a target-oriented attention for its new titles among German sociologists. Compared to all of the small publishers of sociology which have neither the financial nor the personnel resources needed for such efforts, our case is in a better economic situation. The future will show whether the small publishers can somehow manage digitalization and survive, or whether there will be a concentration process as it happened before - on a much higher level - in the field of STM publishing houses.

Another "exogenous shock" German language publishers in the social sciences and humanities have to face now is that especially younger German academics - as everywhere in the world - have gotten under pressure to publish more in international peer-reviewed journals (Savage 2003; Münch 2009: 74; Thiedig 2012). In particular, the appointment to a professorship and further career and income chances highly depend on this. As a consequence, German sociological publishers may begin to lose the best future authors, at least a substantial part of their writing. A program manager of our case complains that there is already "... a lack of really good German-language monographs" (6:394). ${ }^{28}$ Theoretically, these publishers might become more international by publishing English-language books on and beyond the German market. Very few of them - Verlag Barbara Budrich, for

\footnotetext{
28 As some preliminary data suggest, an unintended effect of the pressure to publish in peer-reviewed journals may be a further increase of publications in edited volumes (Thiedig 2012: 37/38, 41/42). Because publication opportunities in journals are scarce, all rejected manuscripts are dumped into such volumes, as a second-worst outcome still better than no publication at all.
} 
instance - try to do that. But each of these German publishing houses lacks the capital needed to become a visible player among American and British publishers. For better or worse, German sociology publishers are caught on the national market. Finally, some years ago - in 2004 - an "endogenous field rupture" started. A dominating "challenger" with a "catch all" strategy has emerged among German sociology publishers which pursues an aggressive growth strategy and has the competitive advantage of belonging to Springer. Two medium-sized social science publishers - Westdeutscher Verlag and Leske ? Budrich - merged under the umbrella first named VS Verlag für Sozialwissenschaften, now Springer VS and became the market leader immediately. This "challenger's" behavior has increased the overall degree of competition within the field, especially as a result of its growth strategy, as a program manager from our case remarks: $(\leftarrow$ p. 208)

I think the competitive pressure has increased for sure. That's one conclusion I would make. 15 years ago there was no VS Verlag (6:220).

The new structure of the organizational field is experienced as a "simultaneity of the non-simultaneous"' $(6: 704)$ by which is meant that now a publisher with a rigorously new business approach competes with all the traditional publishers.

In addition, another publisher, which was founded in 1999 - the transcript Verlag - has also grown quite rapidly. It pursues no "catch all" strategy but a business approach which focuses on establishing new thematic fields on the frontiers of sociology. Nevertheless, both the dominating "challenger" Springer VS and the secondary "challenger" transcript Verlag together have shaken the established "settlement" of the field and considerably intensified the competition among publishers for authors and readers. Due to its embeddedness in one of the large STM publishing houses, the market leader is also able to implement digitalization much faster than all the other publishers, which puts additional pressure on them.

There is a real danger, seen from the point of view of the smaller publishers, that many of them might be driven out of the market sooner or later by the mutually reinforcing effects of the three developments just pointed out. With their potential elimination from the market, the selection as well as the structuring function would be strongly weakened. The more a publishing house focuses on quantity, the more the selection function could be affected; and the less publishers strive for “listbuilding"' (Parsons 1989: 20-24) - which means a distinctive identity via 
specialization - the less the structuring function can be maintained.

\section{Conclusion}

In comparison, the two worlds of academic publishing portrayed here - global STM publishers, on the one hand, national social science and humanities publishers, on the other - are very different. What is similar, though, is the fact that economic growth pressures are behind the potential or actual problems in both fields of publishing. Thus, in both "strategic action fields" the traditional "settlement" which ensured that profit-oriented firms take care of the communication demands of science has become precarious:

- The chemistry publisher has to satisfy its investors' expectations of high and growing profits, and if this continues as it has taken place during the last 20 years, this may cause serious damage to the distribution function.

- In contrast, the sociology publisher has to grow in the sense of increasing earnings to be able to pay the costs of digitalization; otherwise, it may become marginalized or even be driven out of the market which would be harmful for the distribution and the structuring function. On the other hand, under present conditions the distribution function and, even more, the structuring function already suffer.

It remains to be seen what will happen in both fields. But as we suggested at the beginning, a deeper understanding of the past and present business approaches in the $(\leftarrow$ p. 209) two worlds of academic publishing is needed to assess potential future scenarios realistically. We hope that, based on our case studies, we have provided some information, both empirical facts and theoretical interpretations, which helps to reach such an understanding.

We also hope that it has become clear that whatever will happen to the academic publishers in both fields will have serious consequences for scientific communication. Perhaps never before in the history of modern science the critical dependence of its communication infrastructure on economic strategies and fates of business firms has become as evident as today. That the different kinds of "market failure" in both worlds of academic publishing may produce substantial negative externalities 
for scientists' collective pursuit of truth and scientific progress is no longer an abstract possibility; developments leading in this direction have already started. It is important that academics in all fields become aware of these dangers to their conditions of work so that collective reflections about what could be done no longer remain confined to small circles, and appropriate countermeasures are taken soon. $(\leftarrow \mathbf{p . 2 1 0})$

Acknowledgments We thank the organizers - Jochen Gläser and Richard Whitley - as well as the participants for helpful comments. In addition, we are grateful to two anonymous reviewers who gave us some very constructive advice.

\section{References}

Arnold, Douglas N., and Henry Cohn. 2012. Mathematicians take a stand. Notices of the American Mathematical Society 59: 828-833.

Becher, Tony, and Paul R. Towler. 2001. Academic tribes and territories: Intellectual enquiry and the culture of disciplines. Buckingham: Open University Press.

Blaschke, Olaf. 2010. Verleger machen Geschichte. Buchhandel und Historiker seit 1945 im deutschbritischen Vergleich. Göttingen: Wallstein.

Boni, Manfred. 2010. Analoges Geld für digitale Zeilen: der Publikationsmarkt der Wissenschaft. Leviathan 38: 293-312.

Bourdieu, Pierre. 1983. Ökonomisches Kapital, kulturelles Kapital, soziales Kapital. In Soziale Ungleichheiten. Sonderband 2, Soziale Welt, ed. Reinhard Kreckel, 183-198. Göttingen: Schwartz.

Bourdieu, Pierre. 1984. Sozialer Raum und "Klassen". In Pierre Bourdieu, Sozialer Raum und "Klassen". Leçon sur la leçon. 2 Vorlesungen. Frankfurt/M. 1985: Suhrkamp, 7-46.

Braun, Tibor. 2006. Gatekeeping in the international journal literature of chemistry. Information Processing and Management 42: 1652-1656.

Brintzinger, Klaus-Rainer. 2010. Piraterie oder Allmende der Wissenschaften? Zum Streit um Open Access und der Rolle von Wissenschaft, Bibliotheken und Markt bei der Verbreitung von Forschungsergebnissen. Leviathan 38: 331-346.

Buroway, Michael. 2005. For public sociology. American Sociological Review 70: 4-28.

Clemens, Elisabeth S., et al. 1995. Careers in print: Books, journals, and scholarly reputations. American Journal of Sociology 101: 433-494.

Dewatripont, Mathias, Victor Ginsburgh, Patrick Legros, and Alexis Walckiers. 2007. Pricing of Scientific Journals and Market Power. Journal of the European Economic Association 5: 400-410. DFG. 2005. Publikationsstrategien im Wandel? Ergebnisse einer Umfrage zum Publikations- und Rezeptionsverhalten unter besonderer Berü cksichtigung von Open Access. Weinheim: VCH-Wiley.

Fligstein, Neil. 2001. Social skill and the theory of fields. Sociological Theory 19: 105-125.

Fligstein, Neil, and Doug McAdam. 2011. Toward a general theory of strategic action fields. Sociological Theory 29: 1-26.

FuE-Datenreport. 2012. Analysen und Berichte. Forschung und Entwicklung in der Wirtschaft 2009/2010. Stifterverband für die deutsche Wissenschaft. Essen. 
Fuchs, Stephan. 1992. The professional quest for truth. A social theory of science and knowledge. Albany: SUNY Press.

Gläser, Jochen, and Stefan Lange. 2007. Wissenschaft. In Handbuch Governance, eds. Arthur Benz, Susanne Lütz, Uwe Schimank and Georg Simonis, 437-451. Wiesbaden: VS.

Gläser, Jochen, et al. 2010. The limits of universality: How field-specific epistemic conditions affect authority relations and their consequences. In Reconfiguring knowledge production: Changing authority relationships in the sciences and their consequences for intellectual innovation, eds. Richard Whitley, Jochen Gläser and Lars Engwall, 291-324. Oxford: Oxford University Press.

Granovetter, Mark. 1973. The strength of weak ties. American Journal of Sociology 78: 1360-1380. Greco,

Albert N., et al. 2006. The state of scholarly journal publishing: 1981-2000. Journal of Scholarly Publishing 37: 155-214.

Greco, Albert N., et al. 2007. The changing college and university library market for university press books and journals: 1997-2004. Journal of Scholarly Publishing 39: 1-32.

Hahn, Ekkehard. 2009. Publikationsverhalten in der Chemie. In Publikationsverhalten in unterschiedlichen wissenschaftlichen Disziplinen: Beiträge zur Beurteilung von Forschungsleistungen, ed. Alexander-von-Humboldt-Stiftung, 104-107. Bonn: Diskussionspaper 12/2009-2. erw. Aufl.

Hanekop, Heidemarie, and Volker Wittke. 2006. Das wissenschaftliche Journal und seine möglichen Alternativen: Veränderungen der Wissenschaftskommunikation durch das Internet. In Internetökonomie der Medienbranche, ed. Svenja Hagenhoff, 201-233. Göttingen: Universitätsverlag.

Hanekop, Heidemarie, and Volker Wittke. 2007. Der Einfluss des Internets auf die Rekonfiguration des Systems wissenschaftlichen Publizierens. In Gesellschaft und die Macht der Technik. Sozioökonomischer und institutioneller Wandel durch Technisierung, eds. Ulrich Dolata and Raymund Werle, 201-220. Frankfurt/M.: Campus.

Haucap, Justus, Tobias Hartwich, and Andre Uhde. 2005. Besonderheiten und Wettbewerbsprobleme des Marktes für r wissenschaftliche Fachzeitschriften. Vierteljahreshefte fü $r$ Wirtschaftsforschung 74(3): $85-107$.

Hömberg, Walter. 2010. Lektor im Buchverlag. UVK: Repräsentative Studie über einen unbekannten Kommunikationsberuf. Konstanz.

Jochum, Uwe. 2009. "Open Access". Zur Korrektur einiger populärer Annahmen. Gö ttingen: Wallstein. Kuhn, Thomas S. 1962. The structure of scientific revolutions. Chicago: University of Chicago Press.

Larsen, Peder Olesen, and Markus von Ins. 2010. The rate of growth in scientific publication and the decline in coverage provided by science citation index. Scientometrics 84: 575-603.

Luhmann, Niklas. 1970. Selbststeuerung der Wissenschaft. In Soziologische Aufklärung. Aufsätze zur Theorie sozialer Systeme, ed. Niklas Luhmann, 232-252. Bd. 1, Opladen 1974: Westdeutscher Verlag.

Luhmann, Niklas. 1990. Die Wissenschaft der Gesellschaft. Frankfurt/M: Suhrkamp.

Morris, Sally. 2008. What is quality in journals publishing? Learned Publishing 21: 4-6.

Mruck, Katja, and Günter Mey. 2008. Using the Internet for scientific publishing: FQS as an example. Poiesis \& Praxis 5: 113-123.

Münch, Richard. 2009. Publikationsverhalten in der Soziologie. In Publikationsverhalten in unterschiedlichen wissenschaftlichen Disziplinen. Beiträge zur Beurteilung von Forschungsleistungen, ed. Alexander von Humboldt-Stiftung, 69-77. Diskussionspapier Nr. 12. Zweite erweiterte Auflage.

Nicholas, David, et al. 2005. In their very own words: Authors and scholarly journal publishing. Learned Publishing 18: 212-220.

Park, Ji-Hong, and Jian Qin. 2007. Exploring the willingness of scholars to accept open access: A grounded theory approach. Journal of Scholarly Publishing 38: 55-84.

Parsons, Paul. 1989. Getting published. The acquisition process at university presses. Knoxville: University of Tennessee Press.

Powell, Walter W. 1985. Getting into print. The decision-making process in scholarly publishing. Chicago: University of Chicago Press.

Rowlands, Ian, and Dave Nicholas. 2006. The changing scholarly communication landscape: An international survey of senior researchers. Learned Publishing 19: 31-55.

Savage, William W. 2003. Scribble, scribble toil and trouble: Forced productivity in the modern university. Journal of Scholarly Publishing 35: 40-46.

Schimank, Uwe. 2010. Reputation statt Wahrheit: Verdrängt der Nebencode den Code? Soziale Systeme 16: $233-242$

Schimank, Uwe, and Ute Volkmann. 2012. Die Ware Wissenschaft. Die fremdreferentiell finalisierte wirtschaftliche Rationalität von Wissenschaftsverlagen. In Wirtschaftliche Rationalität. Soziologische Perspektiven, eds. Anita Engels, and Lisa Knoll, 165-183. Wiesbaden: Springer VS. 
Schuh, Hans. 2012. Befreiungsbewegung. http://www.dradio.de/dlf/sendungen/wib/1912031/.

Schwoerer, Frank. 1998. Die Bücherberge, die ich angerichtet habe. Erinnerungen eines Verlegers. Frankfurt/M: Campus.

Steele, Colin, Linda Butler, and Danny Kingsley. 2006. The publishing imperative: The pervasive impact of publication metrics. Learned Publishing 19: 277-290.

Tananbaum, Greg. 2003. Of wolves and boys: The scholarly communication crisis. Learned Publishing 16: $285-289$.

Taubert, Niels. 2010. Open Access. In Handbuch Wissenschaftspolitik, eds. Dagmar Simon et al., 310 321. Wiesbaden: VS.

Taubert, Niels. 2012. Online Editorial Management-Systeme und die Produktion wissenschaftlicher Fachzeitschriften. Leviathan 40: 297-319.

Thiedig, Christoph. 2012. Publikationsprofile deutscher Soziologie-Professoren-Explorative Fallstudien zum Wandel der Publikationspraxis. Universität Bremen, Fachbereich 08: Bachelor-Thesis.

Thompson, John B. 2005. Books in the digital age. The transformation of academic and higher education publishing in Britain and the United States. Cambridge: Polity Press.

Thornton, Patricia. 2004. Markets from culture. Institutional logics and organizational decisions in higher education publishing. Stanford: Stanford University Press.

UNESCO (ed.). 2007. Open access: Chancen und Herausforderungen - ein Handbuch. Bonn: Deutsche UNESCO Kommission.

UNESCO (ed.). 2010. Science Report 2010. Published by the United Nations Educational, Scientific and Cultural Organization. Paris. Download: http://publishing.unesco.org/details.aspx?\&Code_Livre= 4770\& change $=$ E visited 11 Dec 2012.

von Lucius, Wulf D. 2005. Strukturwandel im wissenschaftlichen Verlag. Soziale Systeme 11: 32-51. von

Lucius, Wulf D. 2005. Verlagswirtschaft. Ökonomische, rechtliche und organisatorische Grundlagen. Konstanz: UVK.

Vries, Saskia C.J. De. 2007. From sailing boat to steamship: The role of the publisher in an open access environment. Learned Publishing 20: 169-201.

Whitley, Richard. 1984. The intellectual and social organization of the sciences. Oxford: Oxford University Press.

Windolf, Paul (ed.). 2005. Finanzmarkt-Kapitalismus. Analysen zum Wandel von Produktionsregimen. Sonderheft 45, Kölner Zeitschrift fü $r$ Soziologie und Sozialpsychologie, Sonderheft 45. Wiesbaden: VS.

Wissenschaftsrat. 2008. Pilotstudie Forschungsrating. Empfehlungen und Dokumentation. Köln: Selbstverlag. 